\title{
Serglycin: at the crossroad of inflammation and malignancy
}

\section{Angeliki Korpetinou ${ }^{1}$, Spyros S. Skandalis' ${ }^{1}$, Vassiliki T. Labropoulou ${ }^{2}$, Gianna Smirlaki $^{1}$, Argyrios Noulas $^{3}$, Nikos K. Karamanos ${ }^{1}$ and Achilleas D. Theocharis ${ }^{1}$ *}

\author{
1 Laboratory of Biochemistry, Department of Chemistry, University of Patras, Patras, Greece \\ ${ }^{2}$ Division of Hematology, University Hospital of Patras, Patras, Greece \\ ${ }^{3}$ Technological Educational Institute, Larissa, Greece
}

Edited by:

Elvira V. Grigorieva, Institute of Molecular Biology and Biophysics SB

RAMS, Russia

Reviewed by:

Robert Friis, University of Bern, Switzerland

Santos Mañes, Consejo Superior de Investigaciones Científicas, Spain

*Correspondence:

Achilleas D. Theocharis, Laboratory of Biochemistry, Department of

Chemistry, University of Patras,

Patras 26500, Greece

e-mail: atheoch@upatras.gr
Serglycin has been initially characterized as an intracellular proteoglycan expressed by hematopoietic cells. All inflammatory cells highly synthesize serglycin and store it in granules, where it interacts with numerous inflammatory mediators, such as proteases, chemokines, cytokines, and growth factors. Serglycin is implicated in their storage into the granules and their protection since they are secreted as complexes and delivered to their targets after secretion. During the last decade, numerous studies have demonstrated that serglycin is also synthesized by various non-hematopoietic cell types. It has been shown that serglycin is highly expressed by tumor cells and promotes their aggressive phenotype and confers resistance against drugs and complement system attack. Apart from its direct beneficial role to tumor cells, serglycin may promote the inflammatory process in the tumor cell microenvironment thus enhancing tumor development. In the present review, we discuss the role of serglycin in inflammation and tumor progression.

Keywords: proteoglycans, serglycin, chondroitin sulfate, inflammation, malignancy

\section{INTRODUCTION}

Proteoglycans (PGs) are complex macromolecules consisted of a core protein covalently linked with glycosaminoglycan (GAG) chains named chondroitin sulfate (CS), dermatan sulfate (DS), keratan sulfate (KS), heparin (HP), and heparan sulfate (HS). GAGs are negatively charged polysaccharides comprised of repeating disaccharides of acetylated hexosamines ( $N$-acetylgalactosamine or $\mathrm{N}$-acetyl-glucosamine) and mainly by uronic acids (D-glucuronic acid or L-iduronic acid) being sulfated at various positions. KS is composed of disaccharides containing $\mathrm{N}$-acetyl-glucosamine and galactose (1). PGs are synthesized by all cells and distributed in all tissues participating in physiological functions and pathologic conditions. According to their localization they can be divided in three main groups, the cellsurface associated PGs, such as syndecans and glypicans, the matrix secreted PGs (e.g., versican, decorin, perlecan) and the intracellular PGs, with serglycin being the only characterized member of this subfamily to date (1). Numerous studies have demonstrated significant modifications in PG expression in the tumor microenvironment and their contribution to carcinogenesis (1, 2). The type and fine structure of GAG chains attached to PGs are markedly affected in the context of malignant transformation as a result of the altered expression of GAG-synthesizing enzymes (3). Structural modifications of GAGs may facilitate tumorigenesis in various ways, modulating the functions of PGs (3).

Serglycin has been initially considered as a hematopoietic PG present in intracellular secretory compartments. Recent studies demonstrated that serglycin is expressed by a variety of cell types and mediates crucial functions in both normal and pathological conditions $(4,5)$. Rat L2 yolk sac tumor serglycin was the first
PG gene to be cloned and remains until today the smallest known core protein $(18 \mathrm{kDa})(6)$. In human, serglycin consists of a small core protein (158 amino acids) containing eight serine/glycine repeats (Figure 1). Each serine of this repeat region is a potential GAG attachment site. The size of the PG varies according to the GAG chain length, number, and type (7). Serglycin is expressed in all normal hematopoietic cells and hematopoietic tumor cell lines (7-17). In mast cells, eosinophils, neutrophils, and platelets, serglycin is stored together with other bioactive molecules in granules and is secreted upon activation. Serglycin is constitutively secreted by lymphocytes and many hematopoietic tumor cell lines $(7,8,16)$. Serglycin is also expressed in non-hematopoietic cells including pancreatic acinar cells (18), chondrocytes (19), smooth muscle cells $(20,21)$, endothelial cells $(20,22,23)$, fibroblasts $(20$, 24, 25), F9, and NCCIT teratocarcinoma cells $(26,27)$, murine embryonic stem cells (28), murine uterine dedicua cells, parietal endoderm, and fetal liver but not yolk sac hematopoietic cells (29). Recently, it was demonstrated that serglycin is highly expressed by aggressive nasopharyngeal cancer cells (30). The type and sulfation of GAG chains attached to the serglycin core protein, varies between different species and cell types $(4,8,16$, $17,22,23,31-43)$. For example, serglycin expressed by human mast calls has been shown to contain both HP and CS chains enriched in disulfated disaccharides [being sulfated at $\mathrm{C} 4$ and C6 of $\mathrm{N}$-acetyl-galactosamine (CS-E)] attached in separate core proteins, whereas mouse mast cells synthesize a hybrid HP/CS-E serglycin. In leukocytes, platelets, myeloma, and endothelial cells, serglycin contains CS chains that are mainly sulfated at $\mathrm{C} 4$ of $\mathrm{N}$ acetyl-galactosamine (CS-4). Interestingly, the sulfation pattern of CS present in serglycin is regulated during differentiation of 
monocytes to macrophages $(44,45)$. In macrophages serglycin is substituted in a higher degree with CS-E compared to monocytes which contain CS-4 chains. The amount of CS-E expressed by macrophages can be further increased upon activation of differentiated macrophages with phorbol 12-myristate 13-acetate (PMA) (46).

\section{STRUCTURE AND REGULATORY ELEMENTS OF THE HUMAN SERGLYCIN GENE}

The human serglycin gene is located in chromosome 10q.22.1 (47, 48 ) and is consisted by an approximately $1.8 \mathrm{~kb}$ of $5^{\prime}$-flanking DNA, three exons, which are separated by two introns of $8.8 \mathrm{~kb}$ (intron 1) and $6.7 \mathrm{~kb}$ (intron 2) (49,50). The $5^{\prime}$-untranslated mRNA and the hydrophobic 27 aminoacid signal peptide of the translated protein are encoded in the first exon, whereas the second exon encodes a 49 aminoacid peptide that represents the amino-terminus of the mature serglycin core protein. Finally, the larger exon 3 codes a 82 aminoacid peptide that contains the GAG attachment region, the carboxy-terminus, and the $3^{\prime}$-untranslated mRNA region (49) (Figure 1). An alternative spliced variant of serglycin lacking exon 2 has been detected in neutrophils and in low levels in HL-60 and may be related with the maturation of promyelocytes to form segmented neutrophils (15). Several putative regulatory sites are present in the $5^{\prime}$-flanking region with E-26 specific family of transcription factors (ETS) site $(-80)$ and the cyclic AMP response element (CRE) half site at -70 to be the most important regulatory elements for constitutive expression (51) (Figure 1). The CRE site is also important for the induced expression of serglycin after treatment with PMA and dibutyryl cyclic AMP (dbcAMP) (51). ETS regulatory elements interact with ETS1 and Friend leukemia integration 1 transcription factor proteins (FLI1). The expression of serglycin was shown to be up-regulated in a number of leukemic cell lines, ones that coincidentally have been shown to express high levels of ETS1 and FLI1 $(9,52)$. The ETS genes encode transcription factors that play important roles in hematopoiesis, angiogenesis, and organogenesis. In the intron 1 a commonly conserved $70 \mathrm{bp}$ Donehower element is found that may has a cis-acting functional role (49). The serglycin gene has also $21 \mathrm{Alu}$ elements, with two of them being located in the $5^{\prime}$ flanking region, 8 in the intron 1 , and 11 in the intron 2 (49) (Figure 1). Alu elements represent one of the most successful of all mobile elements and are primate specific. Alu element inserts in or near a gene have the potential to influence expression of that gene in several ways (53). The expression of serglycin in different cell lines depends also on the methylation status and the presence of DNaseI hypersensitivity sites (DHSS) within the serglycin gene $(49,54)$. Cell-specific DHSS sites have been found in the promoter region, exon 2 and introns of serglycin gene in hematopoietic and endothelial cells $(51,54)$. These sites are short chromatin regions with disturbed nucleosome formation that have increased sensitivity to factors interacting with DNA and regulate transcription. Several of the DHSS appear to be located well within or very close to $A l u$ repeats and this association may play a role in the expression of serglycin (54).

\section{BINDING PARTNERS OF SERGLYCIN}

Several studies have demonstrated that serglycin is capable to interact with biological important molecules (summarized in Table 1). The binding is mediated either through GAG chains or core protein or both moieties are required for high affinity binding to serglycin. CS chains of serglycin mediate the binding to CD44 (55), whereas CS-4 chains with a high proportion of 4 -sulfated disaccharides (more than 87\%) are required for binding to complement components $\mathrm{Clq}$ and mannose binding lectin (MBL) (56). Although CS-4 chains are crucial for binding of serglycin to MBL (56) and collagen type I (57), the overall structure may

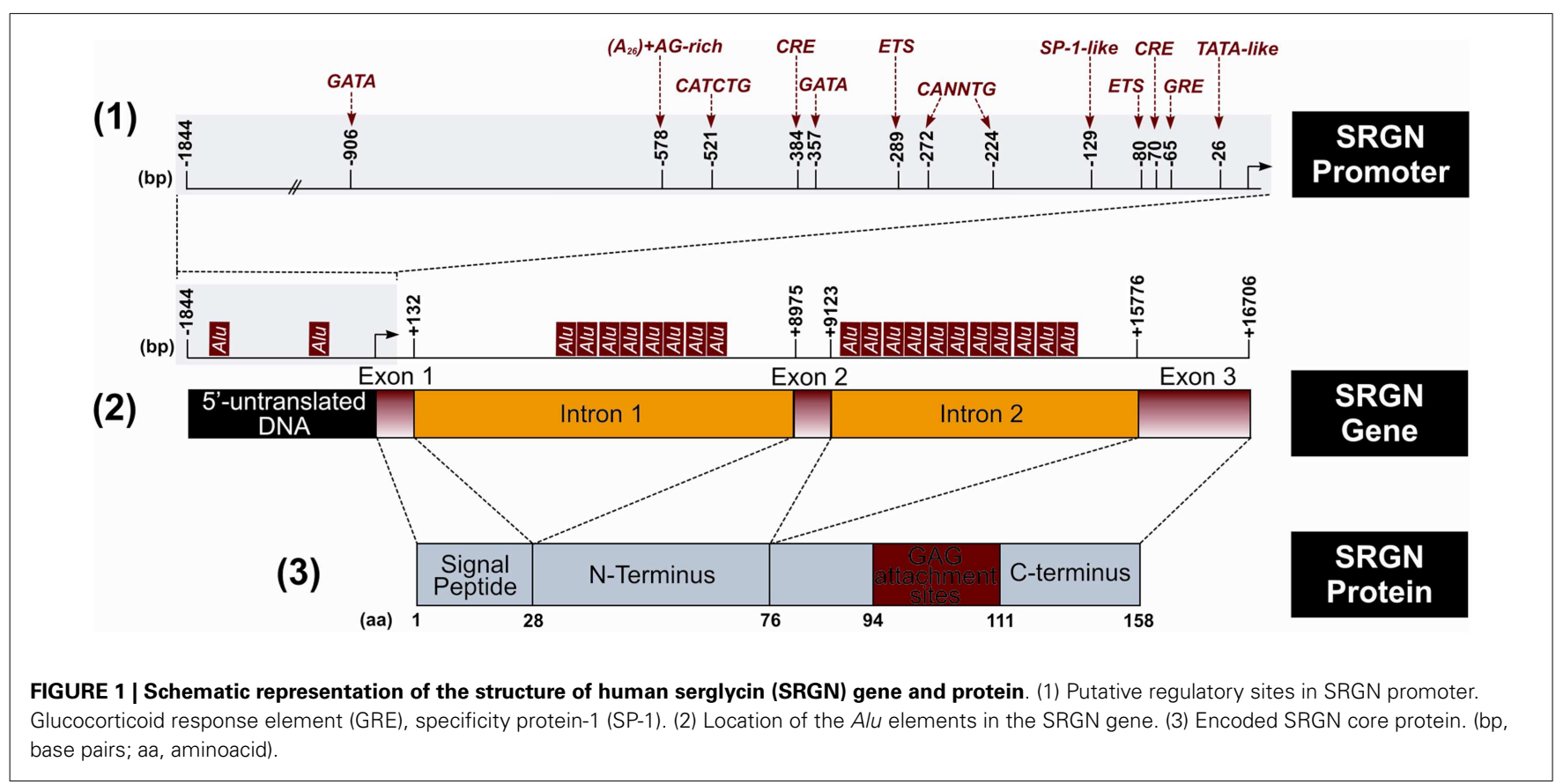


Table 1 | Overview of serglycin binding partners.

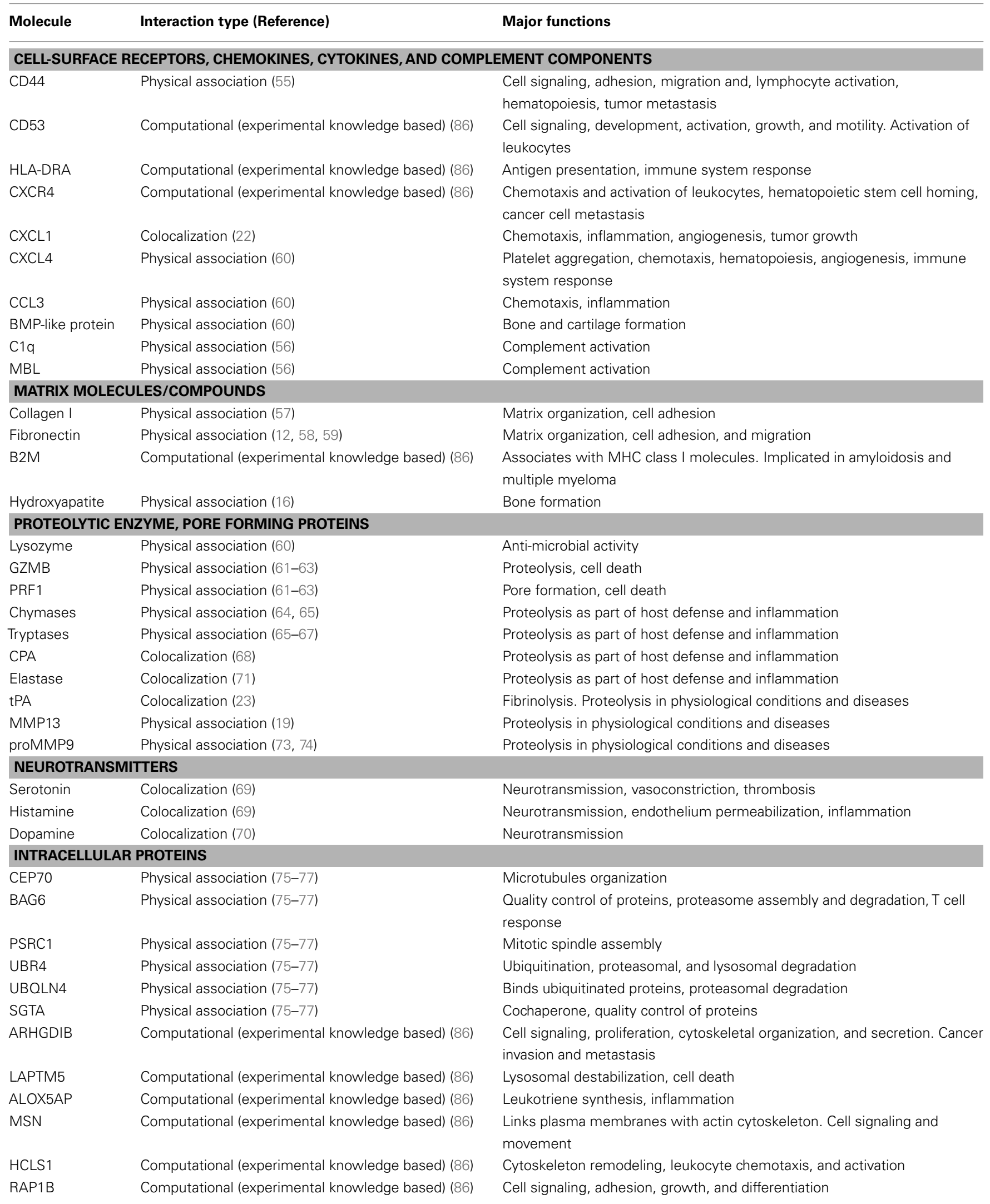


also be important for high affinity binding. This is in agreement with previous studies where the CS-4 chains were essential for binding of serglycin to molecules, such as fibronectin and collagen, chemokine (CXC motif) ligand 4 (CXCL4), chemokine (C-C motif) ligand 3 (CCL3), bone morphogenetic protein (BMP)-like protein, lysozyme, granzyme B (GZMB), perforin (PRF1), and hydroxyapatite although the intact serglycin molecule might interact more efficiently with these molecules (12, 16, 58-63) (Table 1). $\mathrm{HP}$ or/and CS-E chains of serglycin in mast cells mediate its binding to chymases $(64,65)$ and tryptases $(65-67)$ (Table 1). Serglycin colocalizes with carboxypeptidase A (CPA) (68), serotonin, histamine (69), and dopamine (70) in mast cell granules, CPA in pancreatic acinar cells (18), neutrophil elastase in neutrophils (71) and U937 promonocytes (72), tissue-type plasminogen activator (tPA) (23) and chemokine growth-related oncogene-alpha (GRO$\alpha /$ CXCL1) in endothelial cells (22). Serglycin is capable to interact with matrix metalloproteinases (MMPs), such as MMP13 (19) and proMMP9 through its core protein $(73,74)$ (Table 1). By using stringent high-throughput yeast two-hybrid system interactions, novel serglycin ligands, such as centrosomal protein $70 \mathrm{kDa}$ (CEP70), BCL2-associated athanogene 6 (BAG6), proline/serinerich coiled-coil 1 (PSRC1), ubiquitin-protein ligase E3 component n-recognin 4 (UBR4), ubiquilin 4 (UBQLN4), and small glutamine-rich tetratricopeptide repeat (TPR)-containing alpha (SGTA) have been identified (75-77) (Table 1). Among them CEP70 and PSRC1 participate in microtubules formation and assembly of mitotic spindle $(78,79)$, whereas SGTA and BAG6 play key roles in quality control processes for newly synthesized proteins via their ubiquitination and proteasome degradation (80). Recently, it was shown that BAG6 is not only involved in proteasome core particle assembly but also has a key role in efficient regulatory particle assembly by directly associating with precursor regulatory particles (81). UBR4 and UBQLN4 are also involved in the proteasomal degradation of proteins. UBR4 is an E3 ubiquitin-protein ligase that mediates polyubiquitination of low-abundance regulators and selective proteolysis through the proteasome but is also associated with cellular cargoes destined to autophagic vacuoles and degradation through the lysosome $(82,83)$. UBQLN4 binds either to ubiquitinated or not proteins and promotes their proteasomal degradation (84) but also mediates the recruitment of ubiquilin1 to autophagosomes (85). In another study, Wu et al. (86) constructed a protein functional interaction network that suggests association of serglycin with known and novel proteins, such as Rho GDP dissociation inhibitor (GDI) beta (ARHGDIB), CCL3, lysosomal protein transmembrane 5 (LAPTM5), arachidonate 5-lipoxygenase-activating protein (ALOX5AP), chemokine (C-X-C motif) receptor 4 (CXCR4), beta-2 microglobulin (B2M), moesin (MSN), hematopoietic cellspecific Lyn substrate 1 (HCLS1), GZMB, RAP1B, member of RAS oncogene family, major histocompatibility complex, class II, DR alpha (HLA-DRA) (see Table 1). A summary of serglycin interactions is available in http://www.ebi.ac.uk/Tools/webservices/ psicquic/view/main.xhtml?query=srgn. A large number of candidate molecules might associate with serglycin according to STRING database. A diagram with predicted functional partners for serglycin (confidence score $>0.48$ ) is given in Figure 2 (http://string-db.org/).

\section{PHYSIOLOGICAL ROLES OF SERGLYCIN IN INFLAMMATION}

Serglycin synthesized by inflammatory and stromal cells is secreted either constitutively or in a regulated manner. Serglycin secretion can be induced in several cell types upon external inflammatory stimulation. The biosynthesis of serglycin is up-regulated by liposaccharide (LPS) in macrophages (87), tumor necrosis factor (TNF) in endothelial cells (23) and adipocytes (88) and interleukin $1 \beta$ (IL-1 $\beta$ ) in smooth muscle cells (21).

The generation of serglycin ${ }^{-1-}$ mice has demonstrated a wide impact of serglycin on the functional properties of immune cells. In inflammatory cells serglycin is localized in secretory granules and vesicles participating in crucial roles in intracellular storage and secretion of bioactive molecules (Figure 3). In mast cells, serglycin is implicated in the storage of granule-localized proteases such as chymases, tryptases and CPA $(34,68)$, histamine, serotonin, and dopamine in mast cells $(69,70)$. Serglycin forms complexes with mast cell proteases modulating their activities. Several studies have addressed functions linked to HP, the major GAG component of serglycin, in mast cells. HP/chymase complexes bind to HP-binding substrates of the enzyme thus presenting them to chymase and enhancing their proteolysis (89). HP on serglycin was shown to significantly block the inhibition of chymase by natural inhibitors such as alpha 1-protease inhibitor, alpha 1antichymotrypsin, alpha 2-macroglobulin, and soybean trypsin inhibitor $(90,91)$. HP is also involved in the formation of active tryptase tetramers $(92,93)$. It is suggested that serglycin apart from its protective role for partner molecules is also linked to transport to target sites, where proteases are released to perform their functions (94).

Serglycin mediates the storage of GZMB but not of granzyme A in cytotoxic T lymphocytes (CTLs) (95). It is also essential for the storage of elastase in azurophil granules of neutrophils. In contrast, serglycin is not involved in the storage of other granule components such as cathepsin $\mathrm{G}$ and proteinase 3 in these cells (71). Similarly, knockdown of serglycin in platelets results in defective storage of CXCL4, CXCL7, and platelet-derived growth factor (PDGF) (96). The impaired storage of mast cell proteases, neutrophil elastase, GZMB in CTLs and CXCL4 in platelets was not due to altered mRNA levels coding for these molecules, suggesting a crucial role for serglycin on storage rather than mRNA expression. The ability of serglycin to promote storage of granule components is suggested to be due to specific electrostatic interactions between the sulfated GAG chains and the basically charged regions of secretory granule components (95). The stable expression of granule components followed by their diminished protein levels in serglycin knockdown cells and the association of serglycin with SGTA, BAG6, UBR4, and UBQLN4, which are involved in quality control during biosynthesis and degradation of proteins, might suggest a regulatory role for serglycin in cytoplasmic quality control machinery.

Serglycin is also involved in apoptosis and immune regulation. Diminished storage of mast cell proteases in serglycin ${ }^{-1-}$ mice resulted in reduced sensitivity of mast cells to apoptosis as a consequence of the reduced granule damage, reduced release of proteases into the cytosol, and defective caspase- 3 activation (97). Mast cells lacking serglycin expression preferentially died by necrosis rather than apoptosis and the necrotic phenotype of 


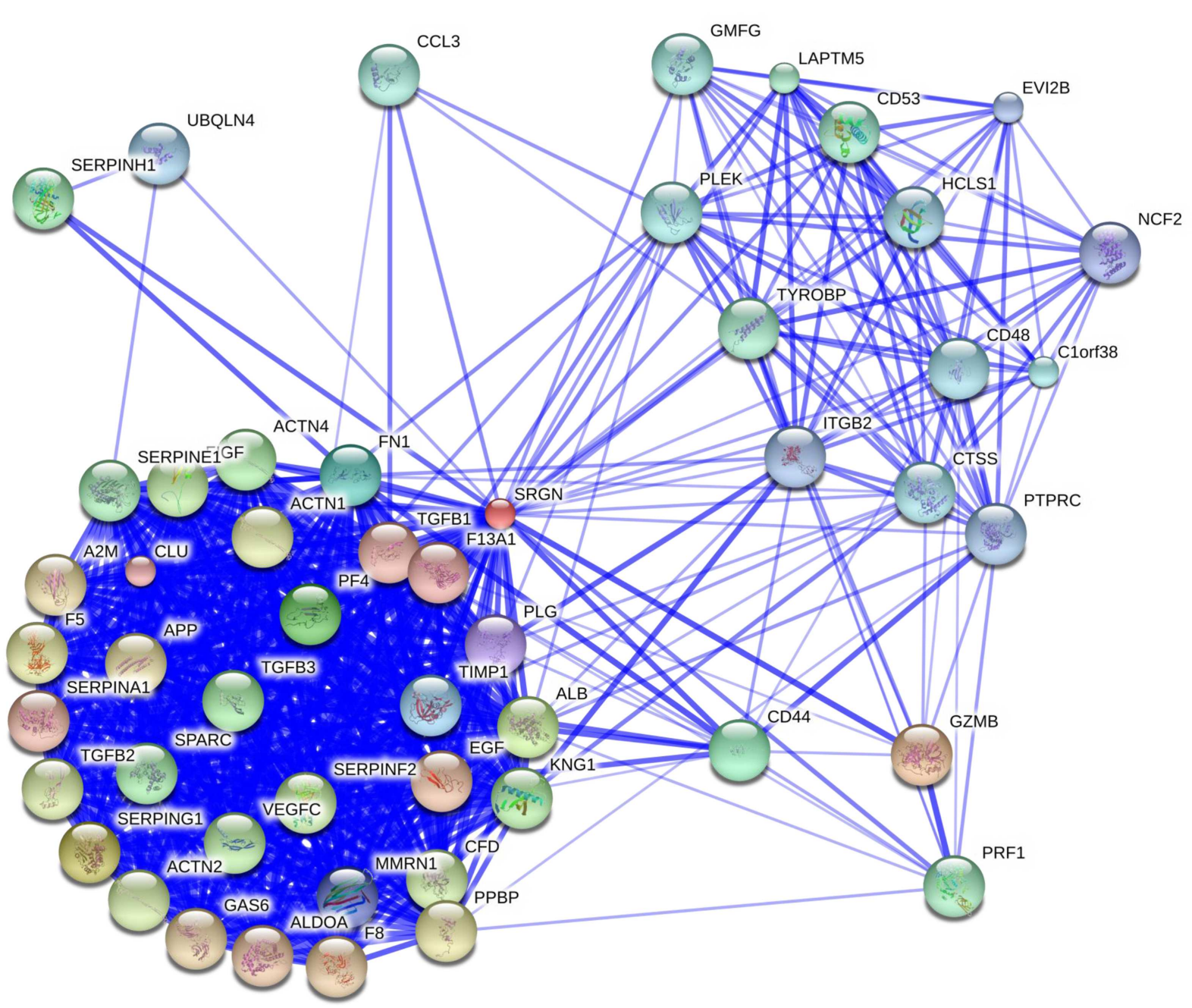

FIGURE 2 | Overlay of predicted functional partners for human serglycin (SRGN). Molecules have been classified according to their confidence score (higher to lower, confidence score $>0.48$ ): GZMB, serpin peptidase inhibitor (SERPING1), albumin (ALB), platelet factor 4/CXCL4 (PF4), CD44, fibronectin 1 (FN1), tissue matrix metalloproteinase inhibitor 1 (TIMP1), multimerin 1 (MMRN1), plasminogen (PLG), clusterin (CLU), coagulation factor XIII, A1 polypeptide (F13A1), TGFB1, serpin peptidase inhibitor, clade A member 1 (SERPINA1), epidermal growth factor (EGF), aldolase A (ALDOA), coagulation factor VIII (F8), growth arrest-specific 6 (GAS6), alpha-2-macroglobulin (A2M), amyloid beta (A4), precursor protein (APP), CXCL7 (PPBP), coagulation factor $\bigvee(F 5)$, actinin, alpha 1 (ACTN1), TGFB2, actinin, alpha 2 (ACTN2), complement factor D (CFD), serpin peptidase inhibitor, clade $F$ (SERPINF2), c-fos induced growth factor/vascular endothelial growth factor D (FIGF), vascular endothelial growth factor C (VEGFC), kininogen 1 (KNG1), actinin, alpha 4 (ACTN4), TGFB3, secreted protein, acidic, cysteine-rich/osteonectin (SPARC), serpin peptidase inhibitor, clade E (SERPINE1), serpin peptidase inhibitor, clade $\mathrm{H}$ (SERPINH1), PRF1, LAPTM5, TYRO protein tyrosine kinase binding protein (TYROBP), CD53, CCL3, glia maturation factor, gamma (GMFG), pleckstrin (PLEK), THEMIS2/thymocyte-expressed molecule involved in selection protein 2 (C1orf38), cathepsin S (CTSS), CD48, HCLS1; UBQLN4; protein tyrosine phosphatase, receptor type, C (PTPRC), integrin, beta-2 (ITGB2), ecotropic viral integration site 2B (EVI2B), neutrophil cytosolic factor 2 (NCF2) (http://string-db.org/). serglycin $^{-1-}$ mast cells was linked to defective degradation of poly(ADP-ribose) polymerase-1 (98). Serglycin binds to GZMB and acts as a vehicle for its delivery from CTLs into target cells $(62,63)$. The impaired storage of GZMB in CTLs and NK cells in serglycin ${ }^{-1-}$ mice may affect their potential to promote killing of neighbor cells $(95,99)$. Interestingly, serglycin ${ }^{-/-}$mice infected with lymphocytic choriomeningitis virus are capable to clear virus as efficient as wild type animal but the contraction of the $\mathrm{CD} 8^{+}$ cells is delayed in serglycin ${ }^{-1-}$ mice, and this could be attributed to sustained proliferation of the $\mathrm{CD}^{+}$cells. The impaired storage of elastase in neutrophils is possibly associated with the reduced capacity of serglycin ${ }^{-1-}$ mice to clear Klebsiella pneumoniae infection (71), whereas after Toxoplasma gondii infection only delayed recruitment of neutrophils and lower levels of IL-6 secretion were demonstrated at early stages of the infection without significant immune response impairment (100).

Another interesting implication of serglycin in the regulation of immune system is its ability to inhibit complement system activity. Serglycin isolated from multiple myeloma (MM) cells inhibits the classical and the lectin pathways of complement system through 


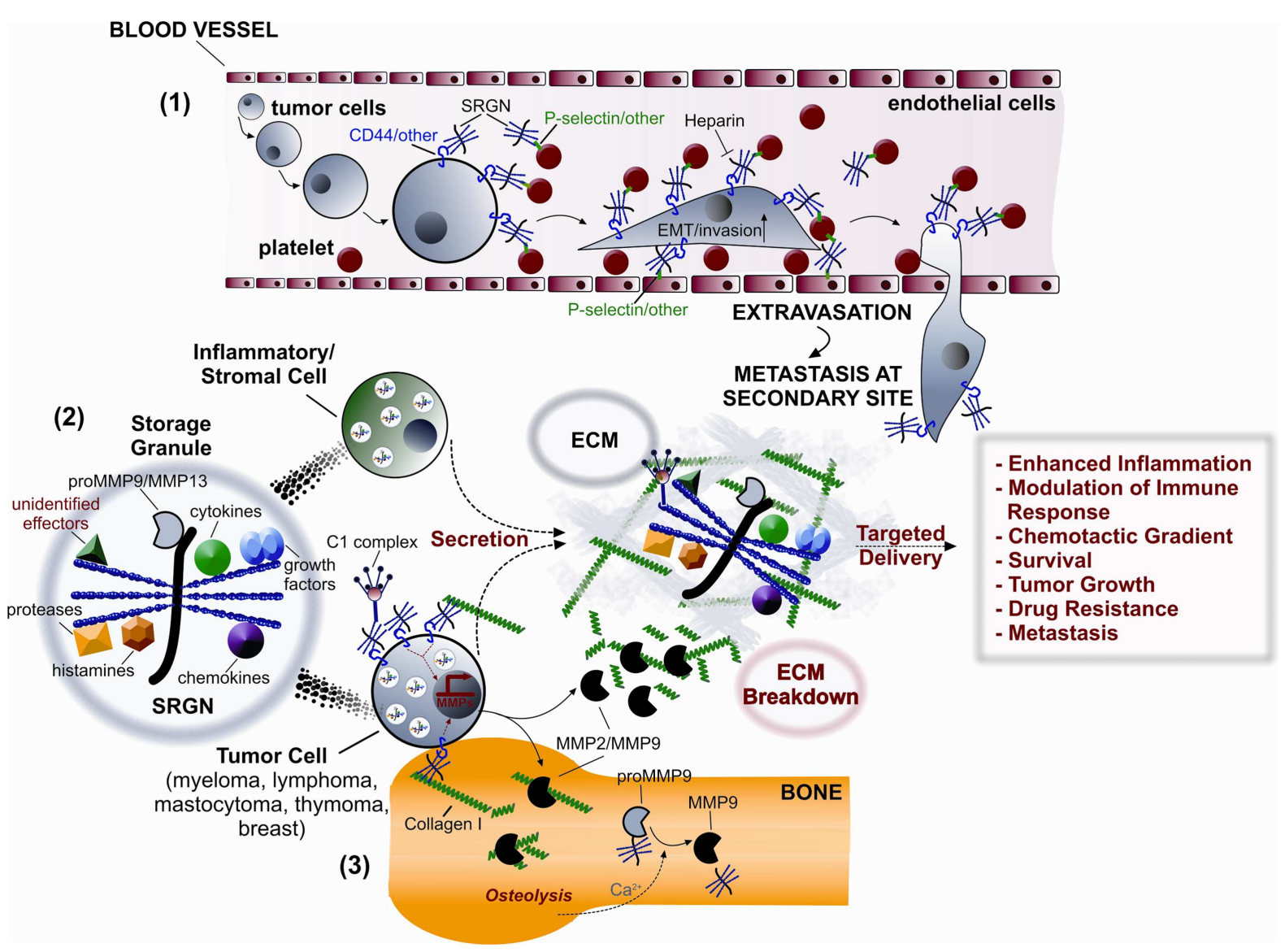

FIGURE 3 | Potential roles of serglycin (SRGN) in inflammation and malignancy. (1) Tumor cells and platelets secrete SRGN, which is subsequently bound on their surface via CD44 and/or other receptors, such as P-selectin. Direct and/or indirect (via SRGN) platelet-tumor cell contacts induce EMT, enhance invasiveness, and promote metastasis by binding to P-selectin and/or other receptors present on endothelial cells. (2) SRGN synthesized by inflammatory/stromal and tumor cells is either constitutively secreted or transported to storage granules for subsequent regulated secretion. SRGN-bound molecular effectors (cytokines, chemokines, complement components, growth factors, proteases, MMPs, histamines, and others) are then specifically delivered to target cells, thus controlling inflammation and tumor progression. (3) SRGN present on tumor cell surface promotes their adhesion to collagen I inducing the expression of MMP2/MMP9 resulting in bone destruction and peritumorous ECM breakdown. binding to $\mathrm{Clq}$ and MBL. CS-4 chains with a high proportion of 4-sulfated disaccharides are required for the interactions with complement proteins (56). CS-E and in a lower extent HP compete with CS-4 chains of serglycin for binding to C1q, whereas only CS-E competes for binding to MBL. Serglycin secreted by various immune cells that carries CS-E or/and HP is more likely capable to regulate the activity of both pathways (56).

In a recent study serglycin was found to be among the most abundantly expressed genes in epicardial adipose tissue and was up-regulated with pro-inflammatory genes such as IL-1 $\beta$, IL-6, IL-8, and chemokine receptor 2 (CCR2) (88). In human umbilical vein endothelial cells (HUVECs) the storage of CXCL1 in secretory vesicles to the apical side was partly depended on serglycin, whereas upon stimulation with IL- $1 \beta$ an increased colocalization of the two molecules inside the vesicles before secretion was observed suggesting a possible involvement of serglycin in inflammatory conditions (22). The presence of serglycin in platelets may be also important for these cells to fully display their pro-inflammatory properties. In platelets, serglycin associates with fibronectin, PDGF, CXCL7, CXCL4, RANTES/CCL5, and CCL3 and its absence leads to reduced storage of PDGF, CXCL4, and CXCL7 in $\alpha$-granules, contributing to defective platelet aggregation and leukocyte activation (96). Serglycin expression is elevated in the dermal vessels in dermatomyositis, a chronic inflammatory disease of the skin (101). In addition, mRNA expression of serglycin is induced upon UVB radiation and IL- $1 \alpha$ exposure in cultured human dermal fibroblasts suggesting that serglycin may participate in dermal inflammation (25).

\section{EXPRESSION AND BIOLOGICAL ROLES OF SERGLYCIN IN MALIGNANCIES}

Although the main function of serglycin in the biology of immune cells is the proper formation of secretory granules and vesicles as well as the storage and secretion of several components in the extracellular matrix (ECM), the role of serglycin in malignancies is rather intriguing. Serglycin seems to participate in tumor 
development in a manner that at least partially requires interactions between tumor cells and their microenvironment (102) (Figure 3).

Serglycin with different GAG chains and sulfation patterns is expressed in numerous human hematopoietic and nonhematopoietic tumors $(8-17,26,27,30,55,103)$. Interestingly, the megakaryocytic tumor cells synthesize a hybrid CS/HS serglycin (12). The expression levels of serglycin may vary during hematopoietic cell differentiation $(9,14,15)$ and is constitutively secreted in the ECM in hematopoietic and solid tumors $(16,30)$. Serglycin has been proposed as a selective biomarker for acute myeloid leukemia compared to Philadelphia chromosomenegative chronic myeloproliferative disorders since it is highly expressed only by leukemic blasts of patients with acute myeloid leukemia and not in acute lymphocytic leukemia (10). Expression of serglycin has been demonstrated in a variety of lymphoma, myeloma, mastocytoma, and thymoma cells. In these cells the presence of CS-4 or CS- 6 side chains of serglycin are required for binding to CD44, whereas serglycin carrying HS or HP is not capable for binding to CD44 $(17,55)$. Secreted serglycin in the tumor microenvironment may interact with CD44 on tumor cells triggering CD44 signaling (Figure 3). CD44 is involved in cell-cell and cell-matrix interactions and signals through several pathways by binding via its cytoplasmic domain to multiple cell membrane and intracellular functional proteins thus regulating cancer cells' epithelial to mesenchymal transition (EMT), migration, metastasis, proliferation, apoptosis, and resistance (104, 105). Importantly, CD44 has been recognized as a cancer stem cell marker for a variety of tumor types.

The expression of serglycin was also confirmed in several MM cell lines (16). Serglycin is the major PG synthesized by MM cells and is constitutively secreted to the culture medium. Interestingly, serglycin is also localized on the cell surface where it is attached through its CS- 4 chains. Serglycin levels are elevated in the bone marrow aspirates of patients with newly diagnosed MM, suggesting a potent correlation of serglycin accumulation with disease progression (16). Serglycin present on myeloma cell surface promotes the adhesion of myeloma cells to collagen I. The adhesion of myeloma cells to collagen I but also the interaction of soluble collagen I with myeloma cells via cell-surface serglycin enhances the biosynthesis and secretion of MMP2 and MMP9, which are involved in bone destruction (57) (Figure 3). The regulatory role of serglycin in the biosynthesis and secretion of proteases has been also shown in other cellular systems $(23,106)$. Serglycin is colocalized with tPA in secretory vesicles in HUVEC (23), whereas Madin-Darby canine kidney cells stably transfected with serglycin express elevated levels of MMP9 and urokinase plasminogen activator (uPA) both at mRNA and protein levels (106). The release of proteolytic enzymes by tumor cells or stromal cells and the regulation of their activity in the tumor microenvironment are crucial for tumor progression and tumor-induced bone disease $(107,108)$. In addition, secreted serglycin was found to influence the bone mineralization process through inhibition of the crystal growth rate of hydroxyapatite, thus providing another possible explanation for impaired bone formation and loss of bone mass commonly seen in MM patients (16). Serglycin synthesized and secreted by human acute monocytic leukemia cell line THP1 as well as serglycin isolated from myeloma cells forms complexes with proform of MMP9 (proMMP9) in vivo and in vitro $(73,74)$. Both the hemopexin-like (PEX) domain and the fibronectin-like (FnII) module of the enzyme are involved in the formation of the heteromer. The formation of heteromers alters the mode of activation of proMMP9 and the interaction of the enzyme with its substrates $(73,109)$. Another study supports the direct protein-protein interaction between serglycin and MMPs (19). It has been shown that serglycin is colocalized with MMP13 in cytoplasmic granules in chondrocytes interacting with a fragment of C-terminal domain of MMP13 that comprises the hinge and PEX domains (19). ProMMP9 in the heteromer is activated in the presence of $\mathrm{Ca}^{2+}$, although this cation stabilizes MMP9 without activating the single proenzyme. $\mathrm{Ca}^{2+}$ induces the cleavage of both the Cterminal PEX domain of the enzyme and the core protein of PG and the release of the activated enzyme. MM located within bone marrow and solid tumors, which metastasize in the bones, induce bone destruction and release $\mathrm{Ca}^{2+}$. The accumulation of serglycin within bone marrow in $\mathrm{MM}$ may be involved in the formation of heteromers with proMMP9 in the ECM triggering a $\mathrm{Ca}^{2+}$-induced activation of the enzyme (Figure 3 ).

Matrix secreted and cell-surface associated serglycin protects myeloma cells from complement system attack induced by immunotherapy, therefore promoting the survival of myeloma cells (56). Serglycin inhibits specifically the classical and the lectin pathways via binding to $\mathrm{C} 1 \mathrm{q}$ and $\mathrm{MBL}$ and do not interfere with the alternative pathway (56) (Figure 3). The intact serglycin molecule is required for binding to $\mathrm{MBL}$, whereas binding to $\mathrm{C} 1 \mathrm{q}$ is mediated exclusively by CS-4 side chains. A similar mode of inhibition of the classical and lectin pathways was demonstrated for secreted serglycin by aggressive breast cancer cells (110). It has been shown previously that complement components such as $\mathrm{C} 1 \mathrm{q}, \mathrm{C} 3, \mathrm{C} 3 \mathrm{a}$, $\mathrm{C} 4, \mathrm{C} 5$, and the membrane attack complex (MAC) are deposited in the inflammatory tumor microenvironment. The assumption has been made is that these activated complement proteins play a role in tumor defense directly through complement-dependent cytotoxicity and indirectly through antibody-dependent cell-mediated cytotoxicity (111). The mechanism of complement activation in cancer is known to involve mainly the classical and the lectin pathways (111). Complement is activated by factors present on tumor cells or induced by treatment of tumor cells with therapeutic antibodies. Malignant cells express a variety of complement inhibitors, which all attenuate complement cytotoxicity (111). The inhibition of complement is also a great limitation during immunotherapy against several types of cancer. These data suggest a role for serglycin as a modulator of immune system response in the tumor microenvironment that may protect tumor cells from complement attack. Another great limitation in the treatment of malignancies is the development of drug resistance. Serglycin is among genes that over-expressed in six tumor cell lines of hematopoietic origin that resist in doxorubicin, methotrexate, cisplatin, and vincristine treatment compared to the drug sensitive parental cell lines (112). The implication of serglycin in drug resistance is of great interest and the mechanism of action is yet unknown.

Only few studies have demonstrated expression of serglycin in non-hematological tumors. Increased expression of serglycin in patients with hepatocellular and nasopharyngeal carcinoma 
was correlated with unfavorable prognosis and represented an independent unfavorable prognostic indicator for overall survival and recurrence as well as disease free and distant metastasis free survival $(30,103)$. Metastatic nasopharyngeal carcinoma cells highly express and secrete in the culture medium serglycin, which promotes motility, invasion, and metastasis (30). The overexpression of serglycin is also associated with EMT in nasopharyngeal cancer cells. The functions of serglycin were dependent on the fully glycosylated molecule. Treatment of cancer cells with exogenously added glycanated serglycin promoted cancer cell metastasis and invasion, whereas non-glycosylated core protein of serglycin failed to induce cell motility (30). In vitro, serglycin was highly expressed and secreted by aggressive tumor cell lines (110). In invasive MDAMB-231 breast cancer cells serglycin represents the major PG type and is abundantly expressed and secreted in the culture medium (110). Furthermore, serglycin is highly expressed by other aggressive breast cancer cells, which also belong to the Basal B subgroup, and they show mesenchymal phenotype, enhanced invasive properties and enriched expression of EMT transcriptional drivers (113). These cells exhibit an EMT gene signature and are found to resemble breast cancer stem cells, being CD $44^{\text {high }} \mathrm{CD} 24^{\text {low }}$ (114). Interestingly, stable overexpression of intact serglycin gene and a truncated form of serglycin lacking GAG attachment sites in low aggressive MCF-7 breast cancer cells demonstrated that serglycin promotes breast cancer cell anchorage-independent growth, migration, and invasion. The tumor promoting properties of serglycin are dependent on the overexpression and secretion of glycanated serglycin (110). Therefore, the specific structure of CS4 present on serglycin is important for serglycin functions in breast cancer. Altered biosynthesis of CS chains has been demonstrated in various cancer types. Specific structures of CS influence various biological processes during tumor growth and spread (115). CHST11 gene that specifically mediates 4-O sulfation of CS is highly expressed in MDA-MB-231 breast cancer cells and breast cancer tissues. CS-4 chains mediate the binding of breast cancer cells to P-selectin and facilitate the formation of metastasis (116).

\section{INFLAMMATION AUGMENTS MALIGNANCY: POSSIBLE ROLES OF SERGLYCIN}

During tumor development, cancer cells produce cytokines and chemokines that attract and activate inflammatory cells, endothelial cells, fibroblasts, and platelets to secrete growth factors, cytokines, and chemokines. Serglycin may regulate the biosynthesis, secretion, and targeted delivery of many inflammatory mediators, which can act in various cell types in paracrine and autocrine manner in multiple ways to enhance inflammatory process and support tumor growth and metastasis (Figure 3).

Tumors are often infiltrated by immune cells, such as T lymphocytes, mast cells, and macrophages, which are recruited to the site by chemokines and cytokines secreted by the various cells in the tumor milieu. Macrophages are attracted by responding to CCL2, IL-4, IL-10, and IL-13, acquire an activated phenotype with pro-tumorigenic properties, releasing a variety of chemokines, cytokines, growth factors, and proteases (117). Mast cells infiltration is occurred in the tumor microenvironment in a number of human malignancies in response to tumor-derived chemoattractants such as CCL2 and CCL5. The presence of mast cells was shown to correlate with either favorable or poor prognosis depending on the tumor. Mast cells can exert pro-tumorigenic effects by secreting factors like VEGF, angiopoietin-1, CXCL1, and IL-8 that promote tumor angiogenesis, as well as growth factors such as PDGF, NGF, SCF, FGF2, and proteases that facilitate tumor cell growth and metastases (118). Mast cell proteases exert dual roles in the regulation of inflammatory process. Several pro-inflammatory chemokines and cytokines are substrates of mast cell proteases and their cleavage results in the activation or inactivation of inflammatory mediators (119). Chymase also indirectly influences ECM remodeling via its ability to activate various MMPs (120, 121). Both tryptase and chymase are directly involved in ECM degradation. Tryptase degrades collagen type IV present in basement membranes while chymase cleaves vitronectin and procollagen and both degrade fibronectin (119).

Endothelial cells synthesize and secrete chemokines, cytokines, and growth factors such as CXCL1 and respond to inflammatory stimuli enhancing their production in a serglycin-depended manner (22). Cancer associated fibroblasts which are activated by cancer cells also overexpress inflammatory mediators as well as serglycin and a disintegrin and metalloproteinase with thrombospondin motifs 1 (ADAMTS1), promoting cancer cell invasion (24).

Considering that single GAG chains and serglycin interact with growth factors, cytokines, and chemokines $(7,122)$, it is plausible that serglycin secreted by cancer and stromal cells is important for the protection of inflammatory mediators in ECM and the creation of chemotactic gradients. Furthermore, serglycin may be involved in the presentation of these molecules to high affinity receptors thus enhancing signaling events (Figure 3 ).

Platelets have long been believed to play a critical role in cancer metastasis through the enhancement of circulating tumor cells survival and adhesion to the endothelium in the circulation (123). Serglycin may be involved in tumor cell metastasis either via its proven role in activation of platelets or directly affecting the binding of tumor cells to platelets (Figure 3). The presence of serglycin in platelets is critical for packaging and secretion of selected $\alpha$-granule proteins. The reduced secretion of dense granule contents results in impaired platelet activation and aggregation $(7,96)$. Tumor cells may bind to the surface of activated platelets via platelet receptors glycoprotein IIb/IIIa (integrin $\alpha I I b \beta 3)$ and P-selectin or by attachment to platelets microparticles. This most likely requires the activation of platelets, the fusion of $\alpha$-granule membrane with the cell membrane, the exposure of activation-induced surface proteins and the secretion of chemokines, cytokines, and growth factors (7). Platelet serglycin may influence the release of these factors in the tumor microenvironment, which promote tumor cell growth and metastasis. Platelet-derived TGF- $\beta$ as well as direct platelet-tumor cell contacts synergistically activate the TGF- $\beta /$ Smad and nuclear factor kappa-light-chain-enhancer of activated B cells (NF- $\mathrm{B}$ ) pathways in cancer cells, resulting in their transition to an invasive mesenchymal-like phenotype and enhanced metastasis in vivo (124) (Figure 3). Another possibility is that released serglycin either by tumor cells or platelets may participate in bridging tumor cells with activated platelets or platelet microparticles as well as endothelial cells. It is proposed that serglycin is bound on the 
surface of platelets (7), whereas serglycin has been identified on the surface of tumor cells $(6,16)$. Secreted serglycin substituted with CS chains may associate with tumor cell surface via CD44 (55) and the membrane of activated platelets and endothelial cells via P-selectin (116) and/or other unidentified receptors (Figure 3). The inhibition of platelets-tumor cell interaction has been targeted for treatment of metastasis. HP and other GAGs isolated from various sources prevent metastasis. Although the anti-metastatic effect of HP was initially believed to associate with its anticoagulant activity, later it was found that interfered with binding of activated platelets with ligands on tumor cells (125).

\section{CONCLUSION}

Serglycin is a dominant PG in immune cells with a major impact on their biology. Numerous studies in the past using mainly a valuable serglycin knockdown mouse model demonstrated important functional roles for serglycin in immune system processes and inflammation. Recent studies have revealed emerging roles for serglycin in tumorigenesis. Collectively, the expression of serglycin seems to benefit tumor cells in multiple ways. It may act as a modulator of immune system in tumor microenvironment and enrich tumor cells with resistance to various therapeutic agents. Serglycin augments the invasion and metastasis of tumor cells with yet unknown molecular mechanisms. Importantly, it serves as an ideal molecular partner for multiple molecular effectors, such as proteolytic enzymes, chemokines, cytokines, and growth factors regulating their biosynthesis and secretion or/and enhancing their activities by protecting and accompanying them to specific target sites.

\section{ACKNOWLEDGMENTS}

This research has been co-financed by the European Union (European Social Fund - ESF) and Greek national funds through the Operational Program "Education and Lifelong Learning" of the National Strategic Reference Framework (NSRF) - Research Funding Program: ARCHIMEDES III. Investing in knowledge society through the European Social Fund.

\section{REFERENCES}

1. Theocharis AD, Skandalis SS, Tzanakakis GN, Karamanos NK. Proteoglycans in health and disease: novel roles for proteoglycans in malignancy and their pharmacological targeting. FEBS J (2010) 277(19):3904-23. doi:10.1111/j.17424658.2010.07800.x

2. Iozzo RV, Sanderson RD. Proteoglycans in cancer biology, tumour microenvironment and angiogenesis. J Cell Mol Med (2011) 15(5):1013-31. doi:10.1111/ j.1582-4934.2010.01236.x

3. Afratis N, Gialeli C, Nikitovic D, Tsegenidis T, Karousou E, Theocharis AD, et al. Glycosaminoglycans: key players in cancer cell biology and treatment. FEBS J (2012) 279(7):1177-97. doi:10.1111/j.1742-4658.2012.08529.x

4. Kolset SO, Pejler G. Serglycin: a structural and functional chameleon with wide impact on immune cells. J Immunol (2011) 187(10):4927-33. doi:10.4049/ jimmunol.1100806

5. Scully OJ, Chua PJ, Harve KS, Bay BH, Yip GW. Serglycin in health and diseases. Anat Rec (Hoboken) (2012) 295(9):1415-20. doi:10.1002/ar.22536

6. Bourdon MA, Oldberg A, Pierschbacher M, Ruoslahti E. Molecular cloning and sequence analysis of a chondroitin sulfate proteoglycan cDNA. Proc Natl Acad Sci U S A (1985) 82(5):1321-5. doi:10.1073/pnas.82.5.1321

7. Schick BP. Serglycin proteoglycan deletion in mouse platelets: physiological effects and their implications for platelet contributions to thrombosis, inflammation, atherosclerosis, and metastasis. Prog Mol Biol Transl Sci (2010) 93:235-87. doi:10.1016/S1877-1173(10)93011-1
8. Kolset SO, Gallagher JT. Proteoglycans in haemopoietic cells. Biochim Biophys Acta (1990) 1032(2-3):191-211.

9. Maillet P, Alliel PM, Mitjavila MT, Perin JP, Jolles P, Bonnet F. Expression of the serglycin gene in human leukemic cell lines. Leukemia (1992) 6(11):1143-7.

10. Niemann CU, Kjeldsen L, Ralfkiaer E, Jensen MK, Borregaard N. Serglycin proteoglycan in hematologic malignancies: a marker of acute myeloid leukemia. Leukemia (2007) 21(12):2406-10. doi:10.1038/sj.leu.2404975

11. Oynebraten I, Hansen B, Smedsrod B, Uhlin-Hansen L. Serglycin secreted by leukocytes is efficiently eliminated from the circulation by sinusoidal scavenger endothelial cells in the liver. J Leukoc Biol (2000) 67(2):183-8.

12. Schick BP, Jacoby JA. Serglycin and betaglycan proteoglycans are expressed in the megakaryocytic cell line CHRF 288-11 and normal human megakaryocytes. J Cell Physiol (1995) 165(1):96-106. doi:10.1002/jcp.1041650113

13. Schick BP, Senkowski-Richardson S. Proteoglycan synthesis in human erythroleukaemia (HEL) cells. Biochem J (1992) 282(Pt 3):651-8.

14. Stellrecht CM, Fraizer G, Selvanayagam C, Chao LY, Lee A, Saunders GF. Transcriptional regulation of a hematopoietic proteoglycan core protein gene during hematopoiesis. J Biol Chem (1993) 268(6):4078-84.

15. Stellrecht CM, Mars WM, Miwa H, Beran M, Saunders GF. Expression pattern of a hematopoietic proteoglycan core protein gene during human hematopoiesis. Differentiation (1991) 48(2):127-35. doi:10.1111/j.1432-0436. 1991.tb00251.x

16. Theocharis AD, Seidel C, Borset M, Dobra K, Baykov V, Labropoulou V, et al. Serglycin constitutively secreted by myeloma plasma cells is a potent inhibitor of bone mineralization in vitro. J Biol Chem (2006) 281(46):35116-28. doi:10.1074/jbc.M601061200

17. Toyama-Sorimachi N, Kitamura F, Habuchi H, Tobita Y, Kimata K, Miyasaka M. Widespread expression of chondroitin sulfate-type serglycins with CD44 binding ability in hematopoietic cells. J Biol Chem (1997) 272(42):26714-9. doi:10.1074/jbc.272.42.26714

18. Biederbick A, Licht A, Kleene R. Serglycin proteoglycan is sorted into zymogen granules of rat pancreatic acinar cells. Eur J Cell Biol (2003) 82(1):19-29. doi:10.1078/0171-9335-00287

19. Zhang L, Yang M, Yang D, Cavey G, Davidson P, Gibson G. Molecular interactions of MMP-13 C-terminal domain with chondrocyte proteins. Connect Tissue Res (2010) 51(3):230-9. doi:10.3109/03008200903288902

20. Kulseth MA, Kolset SO, Ranheim T. Stimulation of serglycin and CD44 mRNA expression in endothelial cells exposed to TNF-alpha and IL-1alpha. Biochim Biophys Acta (1999) 1428(2-3):225-32. doi:10.1016/S0304-4165(99) 00096-3

21. Lemire JM, Chan CK, Bressler S, Miller J, LeBaron RG, Wight TN. Interleukinlbeta selectively decreases the synthesis of versican by arterial smooth muscle cells. J Cell Biochem (2007) 101(3):753-66. doi:10.1002/jcb.21235

22. Meen AJ, Oynebraten I, Reine TM, Duelli A, Svennevig K, Pejler G, et al. Serglycin is a major proteoglycan in polarized human endothelial cells and is implicated in the secretion of the chemokine GROalpha/CXCL1. J Biol Chem (2011) 286(4):2636-47. doi:10.1074/jbc.M110.151944

23. Schick BP, Gradowski JF, San Antonio JD. Synthesis, secretion, and subcellular localization of serglycin proteoglycan in human endothelial cells. Blood (2001) 97(2):449-58. doi:10.1182/blood.V97.2.449

24. Tyan SW, Hsu CH, Peng KL, Chen CC, Kuo WH, Lee EY, et al. Breast cancer cells induce stromal fibroblasts to secrete ADAMTS1 for cancer invasion through an epigenetic change. PLoS One (2012) 7(4):e35128. doi:10.1371/journal.pone. 0035128

25. Werth BB, Bashir M, Chang L, Werth VP. Ultraviolet irradiation induces the accumulation of chondroitin sulfate, but not other glycosaminoglycans, in human skin. PLoS One (2011) 6(8):e14830. doi:10.1371/journal.pone.0014830

26. Grover A, Edwards SA, Bourdon M, Adamson ED. Proteoglycan-19, laminin and collagen type IV production is correlated with the levels of mRNA in F9 cell aggregates differentiating in the presence or absence of cyclic AMP. Differentiation (1987) 36(2):138-44. doi:10.1111/j.1432-0436.1987.tb00188.x

27. Gasimli L, Stansfield HE, Nairn AV, Liu H, Paluh JL, Yang B, et al. Structural remodeling of proteoglycans upon retinoic acid-induced differentiation of NCCIT cells. Glycoconj J (2013) 30(5):497-510. doi:10.1007/s10719-0129450-x

28. Schick BP, Ho HC, Brodbeck KC, Wrigley CW, Klimas J. Serglycin proteoglycan expression and synthesis in embryonic stem cells. Biochim Biophys Acta (2003) 1593(2-3):259-67. doi:10.1016/S0167-4889(02)00396-8 
29. Keith Ho HC, McGrath KE, Brodbeck KC, Palis J, Schick BP. Serglycin proteoglycan synthesis in the murine uterine decidua and early embryo. Biol Reprod (2001) 64(6):1667-76. doi:10.1095/biolreprod64.6.1667

30. Li XJ, Ong CK, Cao Y, Xiang YQ, Shao JY, Ooi A, et al. Serglycin is a theranostic target in nasopharyngeal carcinoma that promotes metastasis. Cancer Res (2011) 71(8):3162-72. doi:10.1158/0008-5472.CAN-10-3557

31. Stevens RL, Fox CC, Lichtenstein LM, Austen KF. Identification of chondroitin sulfate E proteoglycans and heparin proteoglycans in the secretory granules of human lung mast cells. Proc Natl Acad Sci U S A (1988) 85(7):2284-7. doi:10.1073/pnas.85.7.2284

32. Kjellen L, Pettersson I, Lillhager P, Steen ML, Pettersson U, Lehtonen P, et al. Primary structure of a mouse mastocytoma proteoglycan core protein. Biochem $J$ (1989) 263(1):105-13.

33. Lidholt K, Eriksson I, Kjellen L. Heparin proteoglycans synthesized by mouse mastocytoma contain chondroitin sulphate. Biochem J (1995) 311 (Pt 1):233-8.

34. Abrink M, Grujic M, Pejler G. Serglycin is essential for maturation of mast cell secretory granule. J Biol Chem (2004) 279(39):40897-905. doi:10.1074/ jbc.M405856200

35. Yurt RW, Leid RW Jr, Austen KF. Native heparin from rat peritoneal mast cells. J Biol Chem (1977) 252(2):518-21.

36. Gilead L, Livni N, Eliakim R, Ligumsky M, Fich A, Okon E, et al. Human gastric mucosal mast cells are chondroitin sulphate E-containing mast cells. Immunology (1987) 62(1):23-8.

37. Enerback L, Kolset SO, Kusche M, Hjerpe A, Lindahl U. Glycosaminoglycans in rat mucosal mast cells. Biochem J (1985) 227(2):661-8.

38. Stevens RL, Lee TD, Seldin DC, Austen KF, Befus AD, Bienenstock J. Intestinal mucosal mast cells from rats infected with Nippostrongylus brasiliensis contain protease-resistant chondroitin sulfate di-B proteoglycans. J Immunol (1986) 137(1):291-5.

39. Murata K. Acidic glycosaminoglycans in human platelets and leukocytes: the isolation and enzymatic characterization of chondroitin 4-sulfate. Clin Chim Acta (1974) 57(2):115-24. doi:10.1016/0009-8981(74)90418-5

40. Olsson I, Gardell S. Isolation and characterization of glycosaminoglycans from human leukocytes and platelets. Biochim Biophys Acta (1967) 141(2):348-57. doi:10.1016/0304-4165(67)90109-2

41. Metcalfe DD, Wasserman SI, Austen KF. Isolation and characterization of sulphated mucopolysaccharides from rat leukaemic (RBL-1) basophils. Biochem $J$ (1980) 185(2):367-72.

42. Orenstein NS, Galli SJ, Dvorak AM, Silbert JE, Dvorak HF. Sulfated glycosaminoglycans of guinea pig basophilic leukocytes. J Immunol (1978) 121(2):586-92.

43. Schick BP, Walsh CJ, Jenkins-West T. Sulfated proteoglycans and sulfated proteins in guinea pig megakaryocytes and platelets in vivo. Relevance to megakaryocyte maturation and platelet activation. J Biol Chem (1988) 263(2):1052-62.

44. Kolset SO. Oversulfated chondroitin sulfate proteoglycan in cultured human peritoneal macrophages. Biochem Biophys Res Commun (1986) 139(2):377-82. doi:10.1016/S0006-291X(86)80001-8

45. Kolset SO, Kjellen L, Seljelid R, Lindahl U. Changes in glycosaminoglycan biosynthesis during differentiation in vitro of human monocytes. Biochem $\mathrm{J}$ (1983) 210(3):661-7.

46. Uhlin-Hansen L, Eskeland T, Kolset SO. Modulation of the expression of chondroitin sulfate proteoglycan in stimulated human monocytes. $J$ Biol Chem (1989) 264(25):14916-22.

47. Mattei MG, Perin JP, Alliel PM, Bonnet F, Maillet P, Passage E, et al. Localization of human platelet proteoglycan gene to chromosome 10, band q22.1, by in situ hybridization. Hum Genet (1989) 82(1):87-8. doi:10.1007/BF00288281

48. Stevens RL, Avraham S, Gartner MC, Bruns GA, Austen KF, Weis JH. Isolation and characterization of a CDNA that encodes the peptide core of the secretory granule proteoglycan of human promyelocytic leukemia HL-60 cells. J Biol Chem (1988) 263(15):7287-91.

49. Humphries DE, Nicodemus CF, Schiller V, Stevens RL. The human serglycin gene. Nucleotide sequence and methylation pattern in human promyelocytic leukemia HL-60 cells and T-lymphoblast Molt-4 cells. J Biol Chem (1992) 267(19):13558-63.

50. Nicodemus CF, Avraham S, Austen KF, Purdy S, Jablonski J, Stevens RL. Characterization of the human gene that encodes the peptide core of secretory granule proteoglycans in promyelocytic leukemia HL-60 cells and analysis of the translated product. J Biol Chem (1990) 265(10):5889-96.
51. Schick BP, Petrushina I, Brodbeck KC, Castronuevo P. Promoter regulatory elements and DNase I-hypersensitive sites involved in serglycin proteoglycan gene expression in human erythroleukemia, CHRF 288-11, and HL-60 cells. J Biol Chem (2001) 276(27):24726-35. doi:10.1074/jbc.M102958200

52. Papas TS, Watson DK, Sacchi N, Fujiwara S, Seth AK, Fisher RJ, et al. ETS family of genes in leukemia and Down syndrome. Am J Med Genet Suppl (1990) 7:251-61.

53. Deininger P. Alu elements: know the SINEs. Genome Biol (2011) 12(12):236. doi:10.1186/gb-2011-12-12-236

54. Castronuevo P, Thornton MA, McCarthy LE, Klimas J, Schick BP. DNase I hypersensitivity patterns of the serglycin proteoglycan gene in resting and phorbol 12-myristate 13-acetate-stimulated human erythroleukemia (HEL), CHRF 288-11, and HL-60 cells compared with neutrophils and human umbilical vein endothelial cells. J Biol Chem (2003) 278(49):48704-12. doi:10.1074/ jbc.M310220200

55. Toyama-Sorimachi N, Sorimachi H, Tobita Y, Kitamura F, Yagita H, Suzuki K, et al. A novel ligand for CD44 is serglycin, a hematopoietic cell lineage-specific proteoglycan. Possible involvement in lymphoid cell adherence and activation. J Biol Chem (1995) 270(13):7437-44. doi:10.1074/jbc.270.13.7437

56. Skliris A, Happonen KE, Terpos E, Labropoulou V, Borset M, Heinegard D, et al. Serglycin inhibits the classical and lectin pathways of complement via its glycosaminoglycan chains: implications for multiple myeloma. Eur J Immunol (2011) 41(2):437-49. doi:10.1002/eji.201040429

57. Skliris A, Labropoulou VT, Papachristou DJ, Aletras A, Karamanos NK, Theocharis AD. Cell-surface serglycin promotes adhesion of myeloma cells to collagen type I and affects the expression of matrix metalloproteinases. FEBS J (2013) 280(10):2342-52. doi:10.1111/febs.12179

58. Brennan MJ, Oldberg A, Hayman EG, Ruoslahti E. Effect of a proteoglycan produced by rat tumor cells on their adhesion to fibronectin-collagen substrata. Cancer Res (1983) 43(9):4302-7.

59. Schick BP, Pestina TI, San Antonio JD, Stenberg PE, Jackson CW. Decreased serglycin proteoglycan size is associated with the plateletalpha granule storage defect in Wistar Furth hereditary macrothrombocytopenic rats. Serglycin binding affinity to type I collagen is unaltered. J Cell Physiol (1997) 172(1):87-93. doi:10.1002/(SICI)1097-4652(199707)172:1<87::AID-JCP10> 3.0.CO;2- L

60. Kolset SO, Mann DM, Uhlin-Hansen L, Winberg JO, Ruoslahti E. Serglycinbinding proteins in activated macrophages and platelets. J Leukoc Biol (1996) 59(4):545-54.

61. Galvin JP, Spaeny-Dekking LH, Wang B, Seth P, Hack CE, Froelich CJ. Apoptosis induced by granzyme B-glycosaminoglycan complexes: implications for granule-mediated apoptosis in vivo. J Immunol (1999) 162(9): 5345-50.

62. Metkar SS, Wang B, Aguilar-Santelises M, Raja SM, Uhlin-Hansen L, Podack $\mathrm{E}$, et al. Cytotoxic cell granule-mediated apoptosis: perforin delivers granzyme B-serglycin complexes into target cells without plasma membrane pore formation. Immunity (2002) 16(3):417-28. doi:10.1016/S1074-7613(02)00286-8

63. Raja SM, Wang B, Dantuluri M, Desai UR, Demeler B, Spiegel K, et al. Cytotoxic cell granule-mediated apoptosis. Characterization of the macromolecular complex of granzyme B with serglycin. J Biol Chem (2002) 277(51):49523-30. doi:10.1074/jbc.M209607200

64. Pejler G, Maccarana M. Interaction of heparin with rat mast cell protease 1 . J Biol Chem (1994) 269(20):14451-6.

65. Kolset SO, Prydz K, Pejler G. Intracellular proteoglycans. Biochem J (2004) 379(Pt 2):217-27. doi:10.1042/BJ20031230

66. Lindstedt KA, Kokkonen JO, Kovanen PT. Regulation of the activity of secreted human lung mast cell tryptase by mast cell proteoglycans. Biochim Biophys Acta (1998) 1425(3):617-27. doi:10.1016/S0304-4165(98)00115-9

67. Stevens RL, Adachi R. Protease-proteoglycan complexes of mouse and human mast cells and importance of their beta-tryptase-heparin complexes in inflammation and innate immunity. Immunol Rev (2007) 217:155-67. doi:10.1111/j. 1600-065X.2007.00525.x

68. Braga T, Grujic M, Lukinius A, Hellman L, Abrink M, Pejler G. Serglycin proteoglycan is required for secretory granule integrity in mucosal mast cells. Biochem $J$ (2007) 403(1):49-57. doi:10.1042/BJ20061257

69. Ringvall M, Ronnberg E, Wernersson S, Duelli A, Henningsson F, Abrink M, et al. Serotonin and histamine storage in mast cell secretory granules is dependent on serglycin proteoglycan. J Allergy Clin Immunol (2008) 121(4):1020-6. doi:10.1016/j.jaci.2007.11.031 
70. Ronnberg E, Calounova G, Pejler G. Mast cells express tyrosine hydroxylase and store dopamine in a serglycin-dependent manner. Biol Chem (2012) 393(12):107-12. doi:10.1515/BC-2011-220

71. Niemann CU, Abrink M, Pejler G, Fischer RL, Christensen EI, Knight SD, et al. Neutrophil elastase depends on serglycin proteoglycan for localization in granules. Blood (2007) 109(10):4478-86. doi:10.1182/blood-2006-02-001719

72. Lemansky P, Smolenova E, Wrocklage C, Hasilik A. Neutrophil elastase is associated with serglycin on its way to lysosomes in U937 cells. Cell Immunol (2007) 246(1):1-7. doi:10.1016/j.cellimm.2007.06.001

73. Malla N, Berg E, Theocharis AD, Svineng G, Uhlin-Hansen L, Winberg JO. In vitro reconstitution of complexes between pro-matrix metalloproteinase- 9 and the proteoglycans serglycin and versican. FEBS J (2013) 280(12):2870-87. doi:10.1111/febs.12291

74. Winberg JO, Kolset SO, Berg E, Uhlin-Hansen L. Macrophages secrete matrix metalloproteinase 9 covalently linked to the core protein of chondroitin sulphate proteoglycans. J Mol Biol (2000) 304(4):669-80. doi:10.1006/jmbi.2000. 4235

75. Vinayagam A, Stelzl U, Foulle R, Plassmann S, Zenkner M, Timm J, et al. A directed protein interaction network for investigating intracellular signal transduction. Sci Signal (2011) 4(189):rs8. doi:10.1126/scisignal.2001699

76. Lim J, Hao T, Shaw C, Patel AJ, Szabo G, Rual JF, et al. A protein-protein interaction network for human inherited ataxias and disorders of Purkinje cell degeneration. Cell (2006) 125(4):801-14. doi:10.1016/j.cell.2006.03.032

77. Rual JF, Venkatesan K, Hao T, Hirozane-Kishikawa T, Dricot A, Li N, et al. Towards a proteome-scale map of the human protein-protein interaction network. Nature (2005) 437(7062):1173-8. doi:10.1038/nature04209

78. Jang CY, Wong J, Coppinger JA, Seki A, Yates JR III, Fang G. DDA3 recruits microtubule depolymerase Kif2a to spindle poles and controls spindle dynamics and mitotic chromosome movement. J Cell Biol (2008) 181(2):255-67. doi:10.1083/jcb.200711032

79. Kumar A, Rajendran V, Sethumadhavan R, Purohit R. CEP proteins: the knights of centrosome dynasty. Protoplasma (2013) 250(5):965-83. doi:10. 1007/s00709-013-0488-9

80. Leznicki P, High S. SGTA antagonizes BAG6-mediated protein triage. Proc Natl Acad Sci U S A (2012) 109(47):19214-9. doi:10.1073/pnas.1209997109

81. Akahane T, Sahara K, Yashiroda H, Tanaka K, Murata S. Involvement of Bag6 and the TRC pathway in proteasome assembly. Nat Commun (2013) 4:2234. doi: $10.1038 /$ ncomms3234

82. Kim ST, Tasaki T, Zakrzewska A, Yoo YD, Sa Sung K, Kim BY, et al. The N-end rule proteolytic system in autophagy. Autophagy (2013) 9(7):doi:10.4161/auto. 24643

83. Tasaki T, Kim ST, Zakrzewska A, Lee BE, Kang MJ, Yoo YD, et al. UBR box Nrecognin-4 (UBR4), an N-recognin of the N-end rule pathway, and its role in yolk sac vascular development and autophagy. Proc Natl Acad Sci U S A (2013) 110(10):3800-5. doi:10.1073/pnas.1217358110

84. Su V, Nakagawa R, Koval M, Lau AF. Ubiquitin-independent proteasomal degradation of endoplasmic reticulum-localized connexin43 mediated by CIP75. J Biol Chem (2010) 285(52):40979-90. doi:10.1074/jbc.M110.170753

85. Yun Lee D, Arnott D, Brown EJ. Ubiquilin4 is an adaptor protein that recruits Ubiquilin1 to the autophagy machinery. EMBO Rep (2013) 14(4):373-81. doi:10.1038/embor.2013.22

86. Wu G, Feng X, Stein L. A human functional protein interaction network and its application to cancer data analysis. Genome Biol (2010) 11(5):R53 doi:10.1186/gb-2010-11-5-r53

87. Zernichow L, Abrink M, Hallgren J, Grujic M, Pejler G, Kolset SO. Serglycin is the major secreted proteoglycan in macrophages and has a role in the regulation of macrophage tumor necrosis factor-alpha secretion in response to lipopolysaccharide. J Biol Chem (2006) 281(37):26792-801. doi:10.1074/jbc. M512889200

88. Imoto-Tsubakimoto H, Takahashi T, Ueyama T, Ogata T, Adachi A, Nakanishi N, et al. Serglycin is a novel adipocytokine highly expressed in epicardial adipose tissue. Biochem Biophys Res Commun (2013) 432(1):105-10. doi:10.1016/j.bbrc.2013.01.078

89. Pejler G, Sadler JE. Mechanism by which heparin proteoglycan modulates mast cell chymase activity. Biochemistry (1999) 38(37):12187-95. doi:10.1021/ bi991046b

90. Pejler G, Berg L. Regulation of rat mast cell protease 1 activity. Protease inhibition is prevented by heparin proteoglycan. Eur J Biochem (1995) 233(1):192-9. doi:10.1111/j.1432-1033.1995.192_1.x
91. Lindstedt L, Lee M, Kovanen PT. Chymase bound to heparin is resistant to its natural inhibitors and capable of proteolyzing high density lipoproteins in aortic intimal fluid. Atherosclerosis (2001) 155(1):87-97. doi:10.1016/S00219150(00)00544-X

92. Hallgren J, Spillmann D, Pejler G. Structural requirements and mechanism for heparin-induced activation of a recombinant mouse mast cell tryptase, mouse mast cell protease- 6 : formation of active tryptase monomers in the presence of low molecular weight heparin. J Biol Chem (2001) 276(46):42774-81. doi:10.1074/jbc.M105531200

93. Sakai K, Ren S, Schwartz LB. A novel heparin-dependent processing pathway for human tryptase. Autocatalysis followed by activation with dipeptidyl peptidase I. J Clin Invest (1996) 97(4):988-95. doi:10.1172/JCI118523

94. Kolset SO, Tveit H. Serglycin - structure and biology. Cell Mol Life Sci (2008) 65(7-8):1073-85. doi:10.1007/s00018-007-7455-6

95. Grujic M, Braga T, Lukinius A, Eloranta ML, Knight SD, Pejler G, et al. Serglycin-deficient cytotoxic T lymphocytes display defective secretory granule maturation and granzyme B storage. J Biol Chem (2005) 280(39):33411-8. doi:10.1074/jbc.M501708200

96. Woulfe DS, Lilliendahl JK, August S, Rauova L, Kowalska MA, Abrink M, et al. Serglycin proteoglycan deletion induces defects in platelet aggregation and thrombus formation in mice. Blood (2008) 111(7):3458-67. doi:10.1182/ blood-2007-07-104703

97. Melo FR, Waern I, Ronnberg E, Abrink M, Lee DM, Schlenner SM, et al. A role for serglycin proteoglycan in mast cell apoptosis induced by a secretory granulemediated pathway. J Biol Chem (2011) 286(7):5423-33. doi:10.1074/jbc.M110. 176461

98. Melo FR, Grujic M, Spirkoski J, Calounova G, Pejler G. Serglycin proteoglycan promotes apoptotic versus necrotic cell death in mast cells. J Biol Chem (2012) 287(22):18142-52. doi:10.1074/jbc.M112.344796

99. Grujic M, Christensen JP, Sorensen MR, Abrink M, Pejler G, Thomsen AR. Delayed contraction of the CD8+ T cell response toward lymphocytic choriomeningitis virus infection in mice lacking serglycin. J Immunol (2008) 181(2):1043-51.

100. Sawesi O, Spillmann D, Lunden A, Wernersson S, Abrink M. Serglycinindependent release of active mast cell proteases in response to Toxoplasma gondii infection. J Biol Chem (2010) 285(49):38005-13. doi:10.1074/jbc.M110. 118471

101. Kim JS, Werth VP. Identification of specific chondroitin sulfate species in cutaneous autoimmune disease. J Histochem Cytochem (2011) 59(8):780-90. doi:10.1369/0022155411411304

102. Korpetinou A, Milia-Argeiti E, Labropoulou V, Theocharis AD. Serglycin: a novel player in the terrain of neoplasia. In: Karamanos NK, editor. Extracellular Matrix: Pathobiology and Signaling. Berlin: Walter de Gruyter GmbH \& Co. KG (2012). p. 677-88.

103. He L, Zhou X, Qu C, Tang Y, Zhang Q, Hong J. Serglycin (SRGN) overexpression predicts poor prognosis in hepatocellular carcinoma patients. Med Oncol (2013) 30(4):707. doi:10.1007/s12032-013-0707-4

104. Zoller M. CD44: can a cancer-initiating cell profit from an abundantly expressed molecule? Nat Rev Cancer (2011) 11(4):254-67. doi:10.1038/ nrc3023

105. Skandalis SS, Kozlova I, Engstrom U, Hellman U, Heldin P. Proteomic identification of CD44 interacting proteins. IUBMB Life (2010) 62(11):833-40. doi:10.1002/iub.392

106. Zernichow L, Dalen KT, Prydz K, Winberg JO, Kolset SO. Secretion of proteases in serglycin transfected Madin-Darby canine kidney cells. FEBS J (2006) 273(3):536-47. doi:10.1111/j.1742-4658.2005.05085.x

107. Gialeli C, Theocharis AD, Karamanos NK. Roles of matrix metalloproteinases in cancer progression and their pharmacological targeting. FEBS J (2011) 278(1):16-27. doi:10.1111/j.1742-4658.2010.07919.x

108. Labropoulou VT, Theocharis AD, Symeonidis A, Skandalis SS, Karamanos NK, Kalofonos HP. Pathophysiology and pharmacological targeting of tumorinduced bone disease: current status and emerging therapeutic interventions. Curr Med Chem (2011) 18(11):1584-98. doi:10.2174/092986711795471275

109. Winberg JO, Berg E, Kolset SO, Uhlin-Hansen L. Calcium-induced activation and truncation of promatrix metalloproteinase- 9 linked to the core protein of chondroitin sulfate proteoglycans. Eur J Biochem (2003) 270(19):3996-4007. doi:10.1046/j.1432-1033.2003.03788.x

110. Korpetinou A, Skandalis SS, Moustakas A, Happonen KE, Tveit H, Prydz K, et al. Serglycin is implicated in the promotion of aggressive 
phenotype of breast cancer cells. PLoS One (2013) 8(10):e78157. doi:10.1371/ journal.pone.0078157

111. Rutkowski MJ, Sughrue ME, Kane AJ, Mills SA, Parsa AT. Cancer and the complement cascade. Mol Cancer Res (2010) 8(11):1453-65. doi:10.1158/15417786.MCR-10-0225

112. Beyer-Sehlmeyer G, Hiddemann W, Wormann B, Bertram J. Suppressive subtractive hybridisation reveals differential expression of serglycin, sorcin, bone marrow proteoglycan and prostate-tumour-inducing gene I (PTI-1) in drugresistant and sensitive tumour cell lines of haematopoetic origin. Eur J Cancer (1999) 35(12):1735-42. doi:10.1016/S0959-8049(99)00202-6

113. Neve RM, Chin K, Fridlyand J, Yeh J, Baehner FL, Fevr T, et al. A collection of breast cancer cell lines for the study of functionally distinct cancer subtypes. Cancer Cell (2006) 10(6):515-27. doi:10.1016/j.ccr.2006.10.008

114. Blick T, Hugo H, Widodo E, Waltham M, Pinto C, Mani SA, et al. Epithelial mesenchymal transition traits in human breast cancer cell lines parallel the CD44(hi/)CD24 (lo/-) stem cell phenotype in human breast cancer. J Mammary Gland Biol Neoplasia (2010) 15(2):235-52. doi:10.1007/s10911010-9175-z

115. Theocharis AD, Tsolakis I, Tzanakakis GN, Karamanos NK. Chondroitin sulfate as a key molecule in the development of atherosclerosis and cancer progression. Adv Pharmacol (2006) 53:281-95. doi:10.1016/S1054-3589(05)53013-8

116. Cooney CA, Jousheghany F, Yao-Borengasser A, Phanavanh B, Gomes T, KieberEmmons AM, et al. Chondroitin sulfates play a major role in breast cancer metastasis: a role for CSPG4 and CHST11 gene expression in forming surface P-selectin ligands in aggressive breast cancer cells. Breast Cancer Res (2011) 13(3):R58. doi:10.1186/bcr2895

117. Evans A, Costello E. The role of inflammatory cells in fostering pancreatic cancer cell growth and invasion. Front Physiol (2012) 3:270. doi:10.3389/fphys. 2012.00270

118. Protti MP, De Monte L. Immune infiltrates as predictive markers of survival in pancreatic cancer patients. Front Physiol (2013) 4:210. doi:10.3389/fphys.2013. 00210

119. Dai H, Korthuis RJ. Mast cell proteases and inflammation. Drug Discov Today Dis Models (2011) 8(1):47-55. doi:10.1016/j.ddmod.2011.06.004

120. Tchougounova E, Lundequist A, Fajardo I, Winberg JO, Abrink M, Pejler G. A key role for mast cell chymase in the activation of pro-matrix metalloprotease- 9 and pro-matrix metalloprotease-2. J Biol Chem (2005) 280(10):9291-6. doi:10. 1074/jbc.M410396200

121. Saarinen J, Kalkkinen N, Welgus HG, Kovanen PT. Activation of human interstitial procollagenase through direct cleavage of the Leu83-Thr84 bond by mast cell chymase. J Biol Chem (1994) 269(27):18134-40.

122. Zhang L. Glycosaminoglycan (GAG) biosynthesis and GAG-binding proteins. Prog Mol Biol Transl Sci (2010) 93:1-17. doi:10.1016/S1877-1173(10) 93001-9

123. Gay LJ, Felding-Habermann B. Platelets alter tumor cell attributes to propel metastasis: programming in transit. Cancer Cell (2011) 20(5):553-4. doi:10.1016/j.ccr.2011.11.001

124. Labelle M, Begum S, Hynes RO. Direct signaling between platelets and cancer cells induces an epithelial-mesenchymal-like transition and promotes metastasis. Cancer Cell (2011) 20(5):576-90. doi:10.1016/j.ccr.2011.09.009

125. Li J, King MR. Adhesion receptors as therapeutic targets for circulating tumor cells. Front Oncol (2012) 2:79. doi:10.3389/fonc.2012.00079

Conflict of Interest Statement: The authors declare that the research was conducted in the absence of any commercial or financial relationships that could be construed as a potential conflict of interest.

Received: 30 October 2013; accepted: 20 December 2013; published online: 13 January 2014.

Citation: Korpetinou A, Skandalis SS, Labropoulou VT, Smirlaki G, Noulas A, Karamanos NK and Theocharis AD (2014) Serglycin: at the crossroad of inflammation and malignancy. Front. Oncol. 3:327. doi: 10.3389/fonc.2013.00327

This article was submitted to Molecular and Cellular Oncology, a section of the journal Frontiers in Oncology.

Copyright (c) 2014 Korpetinou, Skandalis, Labropoulou, Smirlaki, Noulas, Karamanos and Theocharis. This is an open-access article distributed under the terms of the Creative Commons Attribution License (CC BY). The use, distribution or reproduction in other forums is permitted, provided the original author(s) or licensor are credited and that the original publication in this journal is cited, in accordance with accepted academic practice. No use, distribution or reproduction is permitted which does not comply with these terms. 